\title{
Control of the Surface Charges of Au-Ag Nanorods: Selective Detection of Iron in the Presence of Poly(sodium 4-styrenesulfonate)
}

\author{
Yu-Fen Huang, ${ }^{\dagger}$ Yang-Wei Lin,${ }^{\dagger}$ and Huan-Tsung Chang $*, \dagger, \dagger$ \\ Department of Chemistry, National Taiwan University, 1, Section 4, Roosevelt Road, Taipei, Taiwan, and \\ Department of Natural Science Education, National Taitung University, Taitung, Taiwan
}

Received June 10, 2007. In Final Form: August 29, 2007

\begin{abstract}
In this article, we report a simple approach for selectively sensing $\mathrm{Fe}^{2+}$ ions using $\mathrm{CTAB}$-stabilized $\mathrm{Au}-\mathrm{Ag}$ nanorods (CTAB-Au-Ag NRs) in the presence of poly(sodium 4-styrenesulfonate) (PSS). The prepared CTAB$\mathrm{Au}-\mathrm{Ag}$ NRs exhibit an intense longitudinal surface plasmon resonance absorption $\left(>10^{9} \mathrm{M}^{-1} \mathrm{~cm}^{-1}\right.$ at $\left.827 \mathrm{~nm}\right)$ in the near-infrared region. As a result of attractive electrostatic interactions between PSS and CTAB, agglomeration of the $\mathrm{CTAB}-\mathrm{Au}-\mathrm{Ag}$ NRs induces a change in the absorption at $827 \mathrm{~nm}$. From $\zeta$ potential measurements, we found that the degree of agglomeration was highly dependent on the surface charge density of the $\mathrm{CTAB}-\mathrm{Au}-\mathrm{Ag}$ NRs. Because $\mathrm{Fe}^{2+}\left(\mathrm{Fe}^{3+}\right)$ ions selectively interact with PSS, the degree of agglomeration-and, thus, the change in absorption at $827 \mathrm{~nm}$-is dependent on the concentration of $\mathrm{Fe}^{2+}\left(\mathrm{Fe}^{3+}\right)$ ions. To improve the selectivity of the present sensing system, $\mathrm{Fe}^{3+}$ ions were reduced to $\mathrm{Fe}^{2+}$ ions in the presence of ascorbic acid prior to analysis. The concentrations of $\mathrm{CTAB}-\mathrm{Au}-\mathrm{Ag}$ NRs and PSS are both important parameters in determining the sensitivity and selectivity of the present approach toward sensing $\mathrm{Fe}^{2+}$ ions. Under the optimum conditions [ $34 \mathrm{pM} \mathrm{CTAB}-\mathrm{Au}-\mathrm{Ag} \mathrm{NRs},\left(5 \times 10^{-6}\right) \%$ PSS, pH 7.2], the limit of detection for $\mathrm{Fe}^{2+}$ ions at a signal-to-noise ratio of 3 was $1.0 \mu \mathrm{M}$. We applied this nanosensor system to the determination of $\mathrm{Fe}^{2+}$ in ferritin and in aqueous environmental samples; this approach has the advantages of simplicity, accuracy, and precision (the relative standard deviation from five runs with each sample was below 3\%).
\end{abstract}

\section{Introduction}

The study of metal particles having well-defined nanostructures has become one of the most active research areas in recent decades. ${ }^{1-3}$ Gold nanoparticles (Au NPs) are representative materials that have received considerable attention in areas such as chemical and biological sensing, medical diagnostics, therapeutics, and biological imaging. ${ }^{4-6}$ The surface plasmon resonance (SPR) absorbances of Au NPs are extremely sensitive to the nature, size, and shape of the Au NPs; their interparticle distances; and the nature of their surrounding media. ${ }^{7}$ These fascinating optical properties make Au NPs ideal sensing materials for the selective and sensitive detection of a wide range of analytes, such as DNA, lectin, heavy metal ions, saccharides, aminothiols, and proteins. ${ }^{8-20}$

* To whom correspondence should be addressed. Tel./fax: 011-886-233661171. E-mail: changht@ntu.edu.tw.

National Taiwan University.

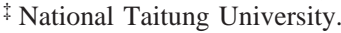

(1) Shipway, A. N.; Katz, E.; Willner, I. ChemPhysChem 2000, 1, 18-52. 615 .

(2) Penn, S. G.; He, L.; Natan, M. J. Curr. Opin. Chem. Biol. 2003, 7, 609-

(3) Roduner, E. Chem. Soc. Rev. 2006, 35, 583-592.

(4) Eustis, S.; El-Sayed, M. A. Chem. Soc. Rev. 2006, 35, 209-217.

(5) Pissuwan, D.; Valenzuela, S. M.; Cortie, M. B. Trends Biotechnol. 2006, $24,62-67$

(6) Hu, M.; Chen, J.; Li, Z.-Y.; Au, L.; Hartland, G. V.; Li, X.; Marquez, M.; Xia, Y. Chem. Soc. Rev. 2006, 35, 1084-1094.

(7) Moores, A.; Goettmann, F. New J. Chem. 2006, 30, 1121-1132.

(8) Elghanian, R.; Storhoff, J. J.; Mucic, R. C.; Letsinger, R. L.; Mirkin, C. A. Science 1997, 277, 1078-1081.

(9) Thanh, N. T. K.; Rosenzweig, Z. Anal. Chem. 2002, 74, 1624-1628.

(10) Hone, D. C.; Haines, A. H.; Russell, D. A. Langmuir 2003, 19, 71417144.

(11) Aslan, K.; Zhang, J.; Lakowicz, J. R.; Geddes, C. D. J. Fluoresc. 2004, 14, 391-400.

(12) Pavlov, V.; Xiao, Y.; Shlyahovsky, B.; Willner, I. J. Am. Chem. Soc. 2004, 126, 11768-11769.

(13) Chen, S.-J.; Chang, H.-T. Anal. Chem. 2004, 76, 3727-3734.

(14) Thaxton, C. S.; Rosi, N. L.; Mirkin, C. A. MRS Bull. 2005, 30, 376-380.

(15) Liu, J.; Lu, Y. J. Am. Chem. Soc. 2005, 127, 12677-12683.

(16) Huang, C.-C.; Huang, Y.-F.; Cao, Z.; Tan, W.; Chang, H.-T. Anal. Chem. 2005, 77, 5735-5741.
When small Au NP seeds grow selectively in certain directions, anisotropic Au nanorods (Au NRs) are formed. Au NRs exhibit two SPR bands, namely, the transverse and longitudinal bands. ${ }^{21}$ Because the longitudinal SPR bands are greater than those of spherical Au NPs and extremely sensitive to changes in aspect ratios, as well as to the dielectric properties of the surroundings, ${ }^{22,23} \mathrm{Au}$ NRs have been recognized as sensitive sensing materials. ${ }^{24-29}$ Core-shell and alloyed multimetallic Au-based nanomaterials that exhibit optical properties that differ from those of Au NRs are also interesting materials. ${ }^{30-33}$ For example, $\mathrm{Au}-$ $\mathrm{Ag} \mathrm{NRs}$ and $\mathrm{Au}-\mathrm{Ag}-\mathrm{Hg} \mathrm{NRs}$ prepared from $\mathrm{Au}$ NR seeds exhibit stronger extinction coefficients and blue shifts of their longitudinal SPR bands relative to those of similarly sized Au NRs, mainly because of the changes in dielectric functions and overall aspect ratios of these nanocomposites. ${ }^{34-36}$ With lon-

(17) Tsai, C.-S.; Yu, T.-B.; Chen, C.-T. Chem. Commun. 2005, 4273-4275. (18) Tseng, W.-L.; Lee, K.-H.; Chang, H.-T. Langmuir 2005, 21, $10676-$ 10683

(19) Huang, Y.-F.; Chang, H.-T. Anal. Chem. 2006, 78, 1485-1493.

(20) Huang, C.-C.; Chang, H.-T. Anal. Chem. 2006, 78, 8332-8338.

(21) Sönnichsen, C.; Franzl, T.; Wilk, T.; von Plessen, G.; Feldmann, J.; Wilson, O.; Mulvaney, P. Phys. Rev. Lett. 2002, 88, 0774021-0774024.

(22) Link, S.; Mohamed, M. B.; El-Sayed, M. A. J. Phys. Chem. B 1999, 103, 3073-3077.

(23) Link, S.; El-Sayed, M. A. J. Phys. Chem. B 2005, 109, 10531-10532.

(24) Yu, C.; Irudayaraj, J. Anal. Chem. 2007, 79, 572-579.

(25) Jain, P. K.; Eustis, S.; El-Sayed, M. A. J. Phys. Chem. B 2006, 110, $18243-18253$

(26) Pan, B.; Ao, L.; Gao, F.; Tian, H.; He, R.; Cui, D. Nanotechnology 2005, $16,1776-1780$

(27) Sudeep, P. K.; Joseph, S. T. S.; Thomas, K. G. J. Am. Chem. Soc. 2005 , 127, 6516-6517.

(28) Rex, M.; Hernandez, F. E.; Campiglia, A. D. Anal. Chem. 2006, 78, $445-451$.

(29) Chen, C.-D.; Cheng, S.-F.; Chau, L.-K.; Wang, C. R. C. Biosens Bioelectron. 2007, 22, 926-932.

(30) Ah, C. S.; Hong, S. D.; Jang, D.-J. J. Phys. Chem. B 2001, 105, 78717873.

(31) Liu, M.; Guyot-Sionnest, P. J. Phys. Chem. B 2004, 108, 5882-5888.

(32) Huang, C.-C.: Yang, Z.; Chang, H.-T. Langmuir 2004, 20, 6089-6092.

(33) Lee, K.-S.; El-Sayed, M. A. J. Phys. Chem. B 2006, 110, 19220-19225.

(34) Yang, Z.; Lin, Y.-W.; Tseng, W.-L.; Chang, H.-T. J. Mater. Chem. 2005 $15,2450-2454$ 
gitudinal SPR bands that are sharper and stronger than those of spherical Au NPs and Au NRs, multimetallic NRs appear to have greater applicability for the sensing of biomolecules.

Sensitive and selective approaches toward the detection of metal ions in biological and environmental samples are important with respect to concerns over toxic exposure to metal ions. Although inductively coupled plasma mass spectrometry (ICPMS) is a powerful technique for the determination of metal ions, it is expensive and not suitable for on-site analysis. Therefore, new techniques, such as nanoprobes, for monitoring aqueous metal ion concentrations are being studied extensively. ${ }^{15,20,24,37-42}$ By taking advantage of the chelating properties of chitosan and the agglomeration-induced changes in the optical properties of Au NPs, chitosan-Au NPs have been employed for the detection of heavy metal ions $\left(\mathrm{Zn}^{2+}\right.$ and $\left.\mathrm{Cu}^{2+}\right) .{ }^{43}$ Significant absorption changes can be observed, however, only at metal ion concentrations on the millimolar level. Thus, we are interested in using nanomaterials having greater molar extinction coefficients. In this regard, metallic NRs are favored over spherical NPs. ${ }^{44}$ Nanorods such as Au NRs, $\mathrm{Au}-\mathrm{Ag} \mathrm{NRs}$, and $\mathrm{Au}-\mathrm{Ag}-\mathrm{Hg}$ NRs are commonly prepared in the presence of templates such as hexadecyltrimethylammonium bromide (CTAB). ${ }^{32,34,45,46}$ However the CTAB-stabilized NRs usually lack selectivity. We point out that the use of CTAB is essential for the formation of anisotropic structures because of its preferential adsorption to the $\{110\}$ facet during the growth process. To improve the selectivity, in this work, we report a simple method for modifying the surface properties of NRs through the use of a polyelectrolyte. We used CTAB-stabilized $\mathrm{Au}-\mathrm{Ag}$ NRs (CTAB-Au-Ag NRs) as representative materials to develop nanoprobes for the selective detection of $\mathrm{Fe}^{2+}$ ions in the presence of poly(sodium 4-styrenesulfonate) (PSS). Because $\mathrm{Fe}^{2+}\left(\mathrm{Fe}^{3+}\right)$ ions disrupt the electrostatic interactions between the positively charged CTAB$\mathrm{Au}-\mathrm{Ag}$ NRs and the negatively charged PSS polyelectrolyte, the extent of charge neutralization-and, thus, os interparticle agglomeration-varies according to the $\mathrm{Fe}^{2+}\left(\mathrm{Fe}^{3+}\right)$ concentration. As a result, changes in color and longitudinal SPR absorption are dependent on the concentration of $\mathrm{Fe}^{2+}\left(\mathrm{Fe}^{3+}\right)$ ions at constant concentrations of $\mathrm{CTAB}-\mathrm{Au}-\mathrm{Ag}$ NRs and PSS. To improve the selectivity of the present sensing system, $\mathrm{Fe}^{3+}$ ions were reduced to $\mathrm{Fe}^{2+}$ ions in the presence of ascorbic acid prior to analysis. This simple nanoprobe allows rapid and accurate determination of the concentrations of $\mathrm{Fe}^{2+}$ in aqueous biological and environmental samples.

\section{Experimental Section}

Chemicals. Glycine, ascorbic acid (L form; 99\%), silver nitrate $\left(\mathrm{AgNO}_{3}, 99 \%\right)$, sodium tetrachloroaurate(III) dihydrate $\left(\mathrm{NaAuCl}_{4}\right.$. $\left.2 \mathrm{H}_{2} \mathrm{O}, 99 \%\right)$, and ferritin $\left(102 \mathrm{mg} \mathrm{mL}^{-1}\right)$ were obtained from Sigma

(35) Huang, Y.-F.; Lin, Y.-W.; Chang, H.-T. Nanotechnology 2006, 17, 48854894

(36) Huang, Y.-F.; Huang, K.-M.; Chang, H.-T. J. Colloid Interface Sci. 2006 $301,145-154$

(37) Kim, Y.; Johnson, R. C.; Hupp, J. T. Nano Lett. 2001, 1, 165-167.

(38) Lin, S.-Y.; Liu, S.-W.; Lin, C.-M.; Chen, C.-H. Anal. Chem. 2002, 74 $330-335$.

(39) Obare, S. O.; Hollowell, R. E.; Murphy, C. J. Langmuir 2002, 18, $10407-$ 10410.

(40) Norsten, T. B.; Frankamp, B. L.; Rotello, V. M. Nano Lett. 2002, 2, $1345-1348$.

(41) He, X.; Liu, H.; Li, Y.; Wang, S.; Li, Y.; Wang, N.; Xiao, J.; Xu, X.; Zhu, D. Adv. Mater. 2005, 17, 2811-2815.

(42) Reynolds, A. J.; Haines, A. H.; Russell, D. A. Langmuir 2006, 22, 11561163

(43) Sugunan, A.; Thanachayanont, C.; Dutta, J.; Hilborn, J. G. Sci. Technol. Adv. Mater. 2005, 6, 335-340.

(44) McFarland, A. D.; Van Duyne, R. P. Nano Lett. 2003, 3, 1057-1062.

(45) Jana, N. R.; Gearheart, L.; Murphy, C. J. J. Phys. Chem. B 2001, 105, 4065-4067.

(46) Nikoobakht, B.; El-Sayed, M. A. Chem. Mater. 2003, 15, 1957-1962.
(St. Louis, MO). CTAB (98\%), iron(II) chloride, and other metallic salts were purchased from Acros Organics (Morris Plains, NJ). Sodium borohydride $\left(\mathrm{NaBH}_{4}, 98 \%\right)$ and PSS $\left(M_{\mathrm{w}}=1 \mathrm{MDa}\right)$ were purchased from Aldrich (Milwaukee, WI). Tris was purchased from J. T. Baker (Phillipsburg, NJ). The values of $\mathrm{pH}$ of solutions containing glycine $(0.5 \mathrm{M})$ and Tris $(0.1 \mathrm{M})$ were adjusted to 8.0 and 7.2, respectively, using 2.0 M NaOH and $\mathrm{HCl}$. Deionized water $(18.2 \mathrm{M} \Omega \mathrm{cm})$ was used to prepare all of the aqueous solutions.

Synthesis of Au NR Seeds. The Au NR seeds were prepared using a slight modification of a seeding method described previously. ${ }^{46}$ Aqueous CTAB solution $(0.2 \mathrm{M}, 5.0 \mathrm{~mL})$ was mixed with $\mathrm{NaAuCl}_{4}(0.5 \mathrm{mM}, 5.0 \mathrm{~mL})$. Ice-cold $0.01 \mathrm{M} \mathrm{NaBH}_{4}(0.6 \mathrm{~mL})$ was added to this solution under sonication. Reaction of this mixture for 3 min resulted in the formation of a brownish-yellow seed solution. In the growth solution, CTAB $(0.2 \mathrm{M}, 50.0 \mathrm{~mL})$ was mixed with $\mathrm{NaAuCl}_{4}(1.0 \mathrm{mM}, 50.0 \mathrm{~mL})$ and $\mathrm{AgNO}_{3}(0.1 \mathrm{M}, 0.1 \mathrm{~mL})$. After gentle mixing of the solution, ascorbic acid $(78.8 \mathrm{mM}, 0.7 \mathrm{~mL})$ was added as a mild reducing agent. The color of the growth solution changed rapidly from dark yellow to colorless, indicating the formation of $\mathrm{AuCl}_{2}$ - ions. Finally, a portion of the seed solution $(0.12 \mathrm{~mL})$ was added to the growth solution. The solution gradually changed color to dark pink over a period of $30 \mathrm{~min}$, indicating the formation of $\mathrm{Au}$ NR seeds. The as-prepared Au NR seed solutions were used directly to prepare the $\mathrm{Au}-\mathrm{Ag}$ NRs without any further purification.

Synthesis of CTAB-Au-Ag NRs. Aliquots $(50.0 \mathrm{~mL})$ of the as-prepared $\mathrm{Au} \mathrm{NR}$ seed solutions (original $\mathrm{pH} \approx 3.0$ ) were mixed with $0.2 \mathrm{M}$ glycine solutions $(50.0 \mathrm{~mL}, \mathrm{pH} 8.0)$; note that the $\mathrm{Au}$ NR seed solutions still contained $\mathrm{Ag}$ and $\mathrm{Au}$ ions, as well as ascorbic acid. ${ }^{34-36}$ These mixtures were incubated without stirring at room temperature overnight to form $\mathrm{Au}-\mathrm{Ag}$ NRs. The sizes of the asprepared $\mathrm{CTAB}-\mathrm{Au}-\mathrm{Ag}$ NRs were verified through TEM analysis (Hitachi H7100, Tokyo, Japan); these nanocomposites appeared to be monodisperse, with average lengths of $56 \pm 7 \mathrm{~nm}$ and widths of $12 \pm 3 \mathrm{~nm}$. A Cintra 10e double-beam UV-vis spectrophotometer (GBC, Victoria, Australia) was used to measure the absorptions of the NR solutions. The transverse and longitudinal absorption bands of the $\mathrm{CTAB}-\mathrm{Au}-\mathrm{Ag}$ NRs were centered at wavelengths of 509 and $827 \mathrm{~nm}$, respectively. The formation of CTAB-Au-Ag NRs was further confirmed through energy-dispersive X-ray, X-ray photoelectron spectroscopy, and ICP-MS measurements. . $^{35,36}$

Reduction and Release of $\mathbf{F e}^{2+}$ Ions from Ferritin. Ferritin $\left(1.0 \mathrm{mg} \mathrm{mL}^{-1}\right)$ in $40.0 \mathrm{mM}$ Tris- $\mathrm{HCl}(\mathrm{pH} 5.0)$ was incubated with $1.0 \mathrm{mM}$ ascorbic acid to reduce $\mathrm{Fe}^{3+}$ to $\mathrm{Fe}^{2+}$ at room temperature for $12 \mathrm{~h}$. A control experiment was performed under the same conditions, but in the absence of ascorbic acid. After releasing $\mathrm{Fe}^{2+}$ ions from the ferritin molecules to the bulk solution, the solutions were subjected to deproteinization through Amicon YM10 membranes (Millipore Corp., Bedford, MA). The filtrates were collected to determine the amounts of $\mathrm{Fe}^{2+}$ ions, using both an ICP-MS system (Elan 6000, Perkin-Elmer, Norwalk, CT) and the Au-Ag NR probes.

Detection of $\mathbf{F e}^{2+}$ Ions. The as-prepared CTAB-Au-Ag NR solutions $(100.0 \mathrm{~mL})$ were subjected to two centrifugation/wash cycles to remove excess $\mathrm{CTAB}$; centrifugation was conducted at $12000 \mathrm{rpm}$ for $10 \mathrm{~min}$, and deionized water $(100.0 \mathrm{~mL})$ was used for washing in each cycle. We note that, after two centrifugation/ wash cycles, the $\mathrm{CTAB}-\mathrm{Au}-\mathrm{Ag}$ NRs were stable in $1.0 \mathrm{mM}$ Tris$\mathrm{HCl}$ solution ( $\mathrm{pH} 7.2$ ) containing 5.0 $\mu \mathrm{M}$ CTAB. For the detection of $\mathrm{Fe}^{2+}$ ions $(0-100.0 \mu \mathrm{M}), \mathrm{CTAB}-\mathrm{Au}-\mathrm{Ag}$ NR pellets were suspended in $1.0 \mathrm{mM}$ Tris- $\mathrm{HCl}$ solutions ( $\mathrm{pH} 7.2)$ containing PSS $\left[(0-5) \times 10^{-5} \%\right]$ and interference metal ions $(0-100.0 \mu \mathrm{M})$. The final concentration of $\mathrm{CTAB}-\mathrm{Au}-\mathrm{Ag}$ NRs was $34 \mathrm{pM}$. The mixtures were equilibrated for $20 \mathrm{~min}$ before absorption measurements were performed. The solutions in the absence and presence of metal ions were then subjected to TEM, absorption, and $\zeta$ potential measurements. The $\zeta$ potential measurements were performed using a Malvern Zetasizer $3000 \mathrm{HS}$ system from Malvern Instruments Ltd. (Malvern, Worcestershire, U.K.). 
(A)

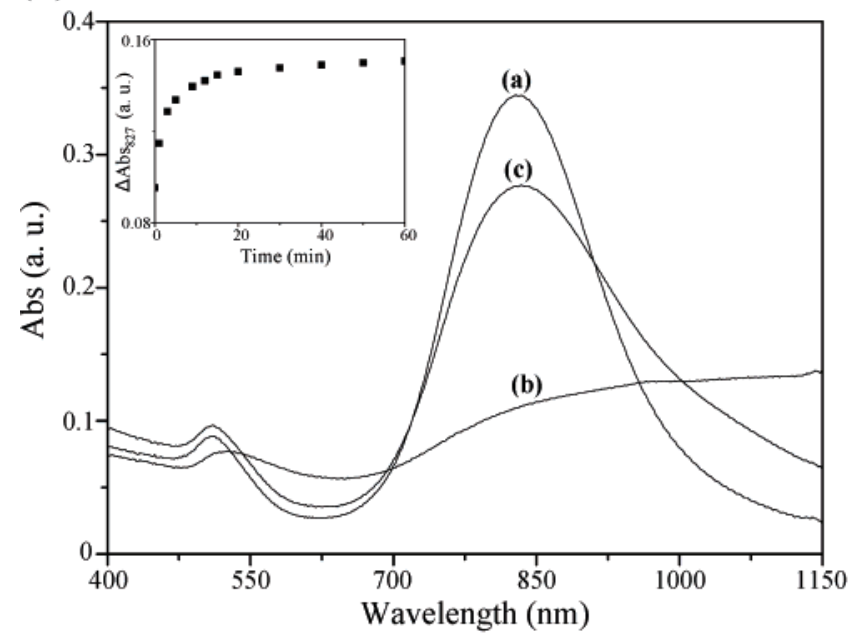

(B)

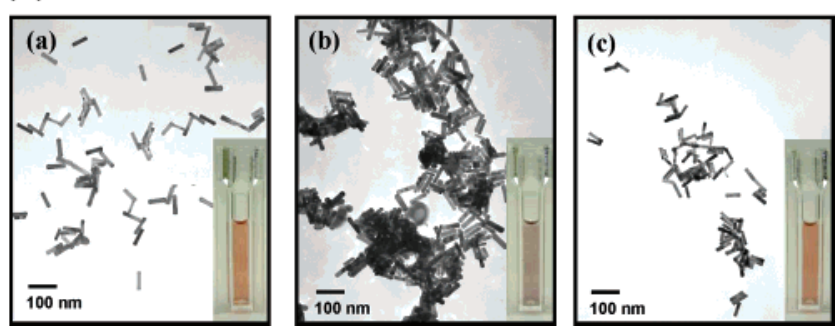

Figure 1. (A) UV-vis absorption spectra and (B) TEM and photographic images of $\mathrm{CTAB}-\mathrm{Au}-\mathrm{Ag}$ NR solutions in the (a) absence and $(\mathrm{b}, \mathrm{c})$ presence of $\left(5 \times 10^{-6}\right) \%$ PSS. $(\mathrm{a}, \mathrm{b}) \mathrm{No} \mathrm{Fe}^{2+}$ ions, (c) $10.0 \mu \mathrm{M} \mathrm{Fe}^{2+}$ ions. Inset to A: Time-course measurements of $\triangle \mathrm{Abs}_{827}$ for $\mathrm{CTAB}-\mathrm{Au}-\mathrm{Ag}$ NRs upon addition of a mixture of PSS $\left[\left(5 \times 10^{-6}\right) \%\right]$ and $\mathrm{Fe}^{2+}(10.0 \mu \mathrm{M})$. The concentration of the $\mathrm{CTAB}-\mathrm{Au}-\mathrm{Ag}$ NRs in $1.0 \mathrm{mM}$ Tris- $\mathrm{HCl}$ solution ( $\mathrm{pH}$ 7.2) was 34 pM.

\section{Results and Discussion}

Sensing Approach. $\mathrm{CTAB}-\mathrm{Au}-\mathrm{Ag}$ NRs having an average aspect ratio of 4.7 exhibit a high molar longitudinal absorptivity (ca. 10 times higher than that of the original Au NRs), ${ }^{32,36}$ and thus, we expected that they could be used as sensitive sensing materials. The longitudinal absorption bands of the CTAB$\mathrm{Au}-\mathrm{Ag}$ NRs undergo red shifts and broaden upon aggregation. By taking advantage of the aggregation-induced changes in color and SPR absorption, we used the as-prepared $\mathrm{Au}-\mathrm{Ag}$ NRs to detect $\mathrm{Fe}^{2+}$ ions in the presence of PSS (an anionic polyelectrolyte). Because $\mathrm{Fe}^{3+}$ ions also selectively interact with PSS, they were reduced to $\mathrm{Fe}^{2+}$ ions by ascorbic acid prior to analysis. Curve a in Figure 1A displays the absorption spectrum of the $\mathrm{CTAB}-\mathrm{Au}-\mathrm{Ag} \mathrm{NRs}$ in $1.0 \mathrm{mM}$ Tris-HCl solution ( $\mathrm{pH} 7.2)$; the maximum wavelengths of the transverse and longitudinal absorptions appear at 509 and $827 \mathrm{~nm}$, respectively. The presence of CTAB bilayers imparts net positive charges to the $\mathrm{Au}-\mathrm{Ag}$ NR surfaces, leading to stable $\mathrm{CTAB}-\mathrm{Au}-\mathrm{Ag}$ NRs in aqueous solution, as indicated in TEM image a in Figure 1B. In the presence of individual metal ions $(100.0 \mu \mathrm{M})$, including $\mathrm{Na}^{+}, \mathrm{K}^{+}, \mathrm{Mg}^{2+}$, $\mathrm{Ca}^{2+}, \mathrm{Sr}^{2+}, \mathrm{Ni}^{2+}, \mathrm{Cu}^{2+}, \mathrm{Zn}^{2+}, \mathrm{Pb}^{2+}, \mathrm{Cd}^{2+}, \mathrm{Hg}^{2+} \mathrm{Co}^{2+}, \mathrm{Au}^{3+}$, $\mathrm{Ag}^{+}, \mathrm{Cr}^{3+}$, and $\mathrm{Fe}^{2+}$, the $\mathrm{CTAB}-\mathrm{Au}-\mathrm{Ag}$ NRs remained quite stable; the absorption spectra of the $\mathrm{CTAB}-\mathrm{Au}-\mathrm{Ag}$ NRs were almost identical in the presence and absence of these metal ions. Next, we added the CTAB-Au-Ag NRs (no metal ions) into a solution containing PSS. As indicated by curve b in Figure 1A, both the transverse and longitudinal absorption bands underwent red shifts (of 17 and $114 \mathrm{~nm}$, respectively), with decreases in their absorbance values of ca. 0.01 and 0.22 arbitrary units (a. u.),

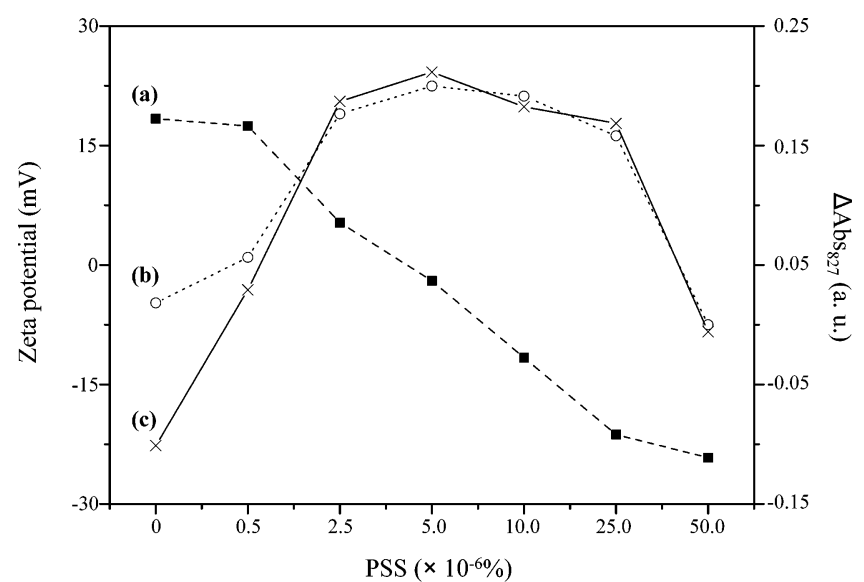

Figure 2. Values of (a) $\zeta$ potential and (b,c) $\Delta \mathrm{Abs}_{827}$ for CTAB$\mathrm{Au}-\mathrm{Ag}$ NR solutions in the presence of various concentrations of PSS. (a,b) No $\mathrm{Fe}^{2+}$ ions, (c) $10.0 \mu \mathrm{M} \mathrm{Fe}{ }^{2+}$ ions. Other conditions were the same as those described in Figure 1.

respectively. Attractive electrostatic interactions between PSS and $\mathrm{CTAB}$ on the $\mathrm{Au}-\mathrm{Ag}$ NR surfaces induced agglomeration, as is evident in TEM image b in Figure 1B. We observe that randomly structured, fractal-like particle/polymer aggregates were formed, mainly because of a lack of spatial and directional control of the interparticle polymer bridging. ${ }^{47-49}$ In the presence of $\mathrm{Fe}^{2+}$ ions, the strength of the electrostatic interactions between PSS and the $\mathrm{CTAB}-\mathrm{Au}-\mathrm{Ag}$ NRs was reduced as a result of the formation of relatively stronger complexes between PSS and $\mathrm{Fe}^{2+}$. PSS is a strong polyelectrolyte containing ionizable sulfonate groups, and it forms dissociated macroion/counterion systems throughout the $\mathrm{pH}$ range from 0 to $14 .^{50}$ Curve $\mathrm{c}$ in Figure 1A and TEM image $\mathrm{c}$ in Figure 1B support our reasoning. The different colors of solutions $\mathrm{a}-\mathrm{c}$ in Figure 1B indicate that this probe allows for the detection of $\mathrm{Fe}^{2+}$ ions by the naked eye. In addition, the TEM images and colors displayed in Figure 1B correlate well with the spectroscopic results. The inset in Figure $1 \mathrm{~A}$ displays a time trace of the absorption differences at $827 \mathrm{~nm}$ $\left(\triangle \mathrm{Abs}_{827}\right)$ in $\mathrm{CTAB}-\mathrm{Au}-\mathrm{Ag} \mathrm{NR}$ solutions containing $(5.0 \times$ $\left.10^{-6}\right) \%$ PSS in the presence of $\mathrm{Fe}^{2+}(10.0 \mu \mathrm{M})$; the greatest absorption difference occurred within $20 \mathrm{~min}$. The value of $\triangle \mathrm{Abs}_{827}$ represents the change in SPR absorbance in the presence and absence of $\mathrm{Fe}^{2+}$ ions. We note that the selectivity and sensitivity of our method become poor at lower and higher $\mathrm{pH}$ values. The interaction between $\mathrm{Fe}^{2+}$ and PSS ions becomes weaker at lower $\mathrm{pH}$ values, whereas the competition of $\mathrm{OH}^{-}$and glycine with PSS ions to from complexes with $\mathrm{Fe}^{2+}$ ions becomes stronger at higher $\mathrm{pH}$ values. At higher glycine concentrations, the selectivity and sensitivity of our method also become poor, mainly because of the formation of complexes between glycine and $\mathrm{Fe}^{2+}$ to a greater extent.

Optimization of PSS Concentration. We performed $\xi$ potential measurements to support our hypothesis of electrostatic interactions between PSS and the CTAB $-\mathrm{Au}-\mathrm{Ag}$ NRs. The $\xi$ potential of the as-prepared $\mathrm{CTAB}-\mathrm{Au}-\mathrm{Ag}$ NRs (purified) was ca. $+18 \mathrm{mV}$ because of the presence of CTAB bilayers on their surfaces. As indicated in Figure 2a, the degree of positive surface charge decreased with increasing PSS concentration over the concentration range from $0 \%$ to $\left(5.0 \times 10^{-6}\right) \%$ and reached zero

(47) Thomas, D. N.; Judd, S. J.; Fawcett, N. Water Res. 1999, 33, 1579-1592. (48) Biggs, S.; Habgood, M.; Jameson, G. J.; Yan, Y.-D. Chem. Eng. J. 2000, $80,13-22$.

(49) Spalla, O. Curr. Opin. Colloid Interface Sci. 2002, 7, 179-185.

(50) Dautzenberg, H.; Jaeger, W.; Kötz, J.; Seidel, C.; Stscherbina, D. Polyelectrolytes. Formation, Characterization and Application; Hanser/Gardner: Munich, Germany, 1994. 
at ca. $\left(5.0 \times 10^{-6}\right) \%$ PSS. Over the PSS concentration range from $\left(5.0 \times 10^{-6}\right) \%$ to $\left(5.0 \times 10^{-5}\right) \%$, the surface charge reversed to negative values and decreased further with increasing PSS concentration. Figure $2 \mathrm{~b}$ exhibits the changes in $\mathrm{Abs}_{827}\left(\Delta \mathrm{Abs}_{827}\right)$ of $\mathrm{CTAB}-\mathrm{Au}-\mathrm{Ag}$ NR solutions at various PSS concentrations (relative to that obtained in the absence of PSS); we observe that the degree of $\mathrm{Au}-\mathrm{Ag} \mathrm{NR}$ agglomeration increased with increasing PSS concentration over the range from $0 \%$ to $\left(5.0 \times 10^{-6}\right) \%$ and reached a maximum value (also a maximum $\Delta \mathrm{Abs}_{827}$ value) when the surface charge was close to zero. Over the concentration range from $\left(5.0 \times 10^{-6}\right) \%$ to $\left(5.0 \times 10^{-5}\right) \%$, the PSS/CTAB$\mathrm{Au}-\mathrm{Ag}$ NR system became increasingly more stable with increasing PSS concentration. At PSS concentrations above (5.0 $\left.\times 10^{-5}\right) \%$, the PSS/CTAB-Au-Ag NR system was stable and monodisperse as a result of electrostatic repulsion. These results suggest that the agglomeration of $\mathrm{CTAB}-\mathrm{Au}-\mathrm{Ag}$ NRs is highly dependent on their surface charge densities, supporting the existence of an electrostatic attraction between PSS and the $\mathrm{CTAB}-\mathrm{Au}-\mathrm{Ag}$ NRs. To optimize the PSS concentration for the detection of $\mathrm{Fe}^{2+}$, we plotted the values of $\triangle \mathrm{Abs}_{827}$ of CTAB$\mathrm{Au}-\mathrm{Ag}$ NR solutions containing $10.0 \mu \mathrm{M} \mathrm{Fe}^{2+}$ against the PSS concentration (Figure 2c). As expected, the maximum value of $\Delta \mathrm{Abs}_{827}$ was achieved at a PSS concentration of $\left(5.0 \times 10^{-6}\right) \%$. The $\zeta$ potentials of the $\mathrm{CTAB}-\mathrm{Au}-\mathrm{Ag}$ NRs in solutions containing $\left(5.0 \times 10^{-6}\right) \%$ PSS in the absence and presence of $10.0 \mu \mathrm{M} \mathrm{Fe}^{2+}$ ions were -2 and $+18 \mathrm{mV}$, respectively. These results support our reasoning that the interaction between PSS and $\mathrm{CTAB}-\mathrm{Au}-\mathrm{Ag}$ NRs was suppressed in the presence of $\mathrm{Fe}^{2+}$ ions. We selected a PSS concentration of $\left(5.0 \times 10^{-6}\right) \%$ for all subsequent experiments.

Selectivity of the CTAB-Au-Ag NR Probe. To test the selectivity of the $\mathrm{CTAB}-\mathrm{Au}-\mathrm{Ag} \mathrm{NR}$ probe toward $\mathrm{Fe}^{2+}$ ions, we conducted experiments similar to those used to obtain image $\mathrm{c}$ in Figure 1B, but with the addition of various other metal ions, including $\mathrm{Na}^{+}, \mathrm{K}^{+}, \mathrm{Mg}^{2+}, \mathrm{Ca}^{2+}, \mathrm{Sr}^{2+}, \mathrm{Ni}^{2+}, \mathrm{Cu}^{2+}, \mathrm{Zn}^{2+}, \mathrm{Pb}^{2+}$, $\mathrm{Cd}^{2+}, \mathrm{Hg}^{2+}, \mathrm{Co}^{2+}$, and $\mathrm{Au}^{3+}$ (each at a concentration of 100.0 $\mu \mathrm{M})$ and $\mathrm{Ag}^{+}$and $\mathrm{Cr}^{3+}(10.0 \mu \mathrm{M})$. Compared to the effect $\left(\Delta \mathrm{Abs}_{827}=0.19\right)$ of $10.0 \mu \mathrm{M} \mathrm{Fe}^{2+}$, the changes induced by the other metal ions were much smaller (Figure 3A). Considering the chemical structure of PSS, we did not expect chelate formation with the metal ions. In terms of Pearson's concept of hard and soft acids and bases, sulfonate is in the middle of the series of Lewis bases. ${ }^{51}$ As a general rule, hard acids coordinate better with hard bases and soft acids with soft bases. Thus, the middle Lewis acid/base combination of $\mathrm{Fe}^{2+}$ and PSS was favorable in our experiments (Lewis acid strength order: $\mathrm{Na}^{+}>\mathrm{K}^{+}>\mathrm{Mg}^{2+}$ $>\mathrm{Ca}^{2+}>\mathrm{Sr}^{2+}>\mathrm{Fe}^{2+}>\mathrm{Cr}^{3+}>\mathrm{Pb}^{2+}>\mathrm{Cu}^{2+}>\mathrm{Co}^{2+}>\mathrm{Zn}^{2+}$ $\left.>\mathrm{Ni}^{2+}>\mathrm{Cd}^{2+}>\mathrm{Hg}^{2+}>\mathrm{Ag}^{+}>\mathrm{Au}^{3+}\right) .{ }^{52}$ The induced changes were greater for $\mathrm{Ag}^{+}$and $\mathrm{Cr}^{3+}$ than for the other interference metal ions, mainly because the former form stable complexes with bromide (from CTAB) and PSS, respectively. In addition, $\mathrm{Ag}^{+}$might have been reduced to $\mathrm{Ag}$ atoms by the residual ascorbic acid in the solution. Fortunately, these two ions in most biological and environmental samples are present at concentrations well below that of $\mathrm{Fe}^{2+}$, and thus, we expect that their interference with this present probe will usually be negligible. To further test the practicality of $\mathrm{CTAB}-\mathrm{Au}-\mathrm{Ag} \mathrm{NR}$ probe, we conducted both absorption and $\zeta$ potential measurements in mixtures containing $\mathrm{Fe}^{2+}(10.0 \mu \mathrm{M})$ and possible interference ions such as $\mathrm{Na}^{+}, \mathrm{K}^{+}, \mathrm{Ni}^{2+}, \mathrm{Cu}^{2+}, \mathrm{Zn}^{2+}, \mathrm{Pb}^{2+}, \mathrm{Cd}^{2+}, \mathrm{Hg}^{2+}, \mathrm{Co}^{2+}$, and $\mathrm{Au}^{3+}$ (each at a concentration of $100.0 \mu \mathrm{M}$ ) and $\mathrm{Ag}^{+}$and $\mathrm{Cr}^{3+}$

(51) Rivas, B. L.; Schiappacasse, L. N.; Pereira, U. E.; Moreno-Villoslada, I. Polymer 2004, 45, 1771-1775. 225 .

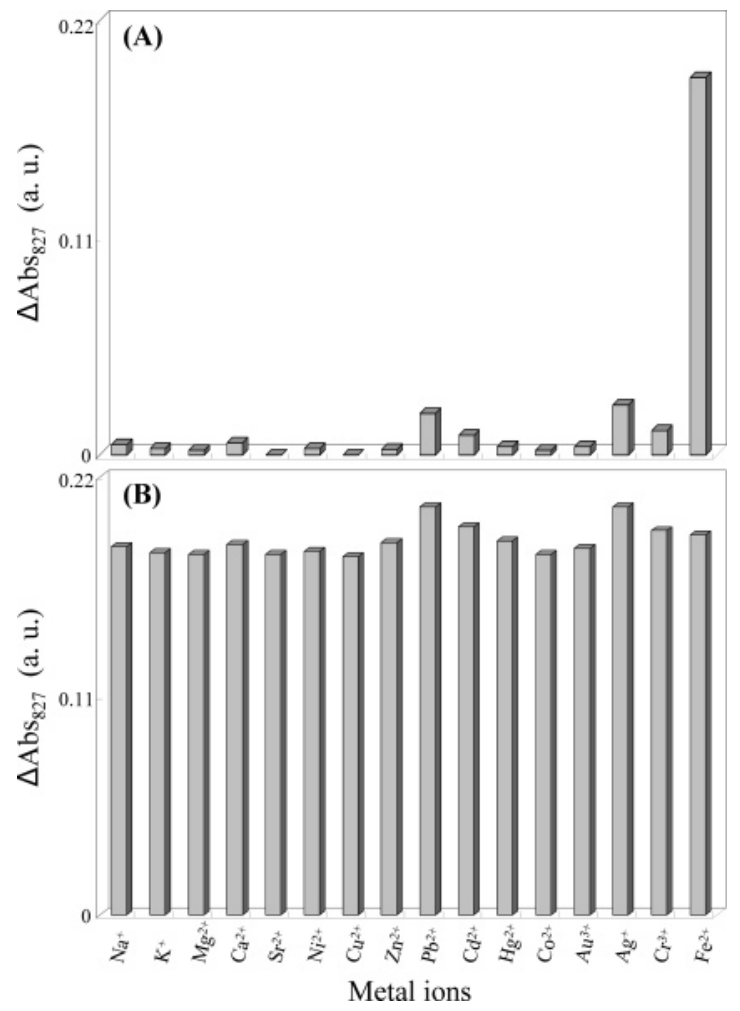

Figure 3. Values of $\Delta \mathrm{Abs}_{827}$ of the $\mathrm{CTAB}-\mathrm{Au}-\mathrm{Ag}$ NR solutions in the presence of $(\mathrm{A})$ various metal ions and $(\mathrm{B}) \mathrm{Fe}^{2+}$ ions $(10.0$ $\mu \mathrm{M})$ and various metal ions. In $\mathrm{A}$, the concentrations of $\mathrm{Fe}^{2+}, \mathrm{Ag}^{+}$, and $\mathrm{Cr}^{3+}$ ions were $10.0 \mu \mathrm{M}$; those of the other ions were $100.0 \mu \mathrm{M}$. In $\mathrm{B}$, the concentrations of $\mathrm{Ag}^{+}$and $\mathrm{Cr}^{3+}$ ions are $10.0 \mu \mathrm{M}$; those of the other ions are $100.0 \mu \mathrm{M}$. In both case, other conditions were the same as those described in Figure 1.

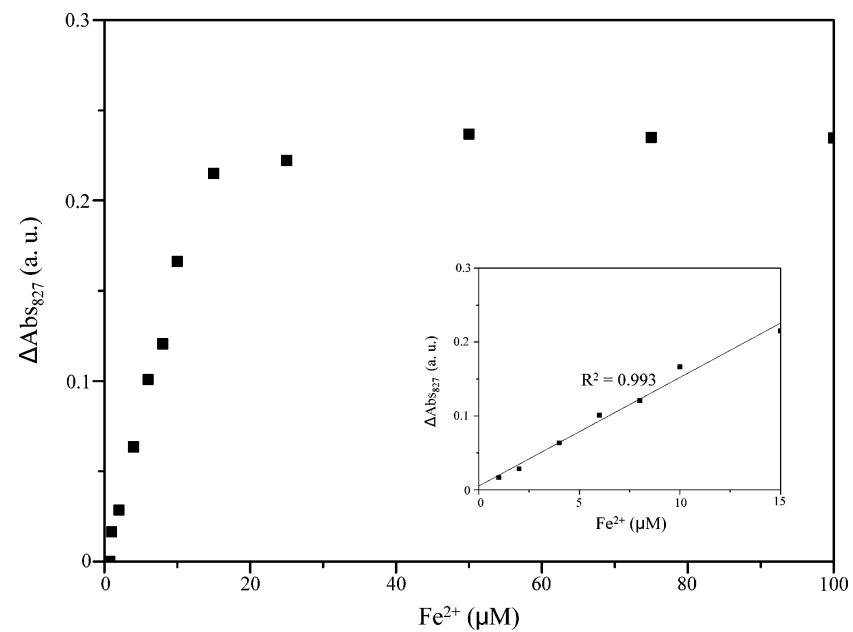

Figure 4. Plot of the values of $\Delta \mathrm{Abs}_{827}$ of $\mathrm{CTAB}-\mathrm{Au}-\mathrm{Ag} \mathrm{NR}$ solutions as a function of $\mathrm{Fe}^{2+}$ concentration $(0-100.0 \mu \mathrm{M})$ in the presence of PSS $\left[\left(5 \times 10^{-6}\right) \%\right]$. Other conditions were the same as those described in Figure 1.

$(10.0 \mu \mathrm{M})$. The resulting absorption data (Figure 3B) demonstrate that the high selectivity of the $\mathrm{CTAB}-\mathrm{Au}-\mathrm{Ag}$ NR probe toward $\mathrm{Fe}^{2+}$ ions in presence of other metal ions still counts. The differences in the values of $\zeta$ potential in the solutions containing $\mathrm{Fe}^{2+}$ ions in the absence and presence of the other metal ions were always negligible $(<0.9 \mathrm{mV})$.

Sensitivity and Applications. Figure 4 indicates that the value of $\triangle \mathrm{Abs}_{827}$ of the CTAB-Au-Ag NRs $(34 \mathrm{pM})$ in the presence of $\left(5.0 \times 10^{-6}\right) \%$ PSS increased with increasing concentration of $\mathrm{Fe}^{2+}$ ions, with linearity existing over the range from 1.0 to 
$15.0 \mu \mathrm{M}\left(R^{2}=0.993\right)$. The limit of detection (LOD) of $\mathrm{Fe}^{2+}$ ions, at a signal-to-noise ratio of 3 , was $1.0 \mu \mathrm{M}$, suggesting that this probe has great practical potential.

The major intracellular storage form of iron is ferritin, a spherical protein consisting of 24 subunits surrounding an aqueous cavity capable of accommodating up to 4500 iron atoms as a ferrihydrite iron(III) core. ${ }^{53-55}$ Release of iron ions from ferritin has been studied extensively, with the aim of understanding how the iron ions are mobilized from the ferritin store to biological fluids under certain conditions, usually as a response to oxidative stress. The progression of certain neurodegenerative diseases is related to an unusual release of iron from ferritin. ${ }^{56-58}$ To test the practicality of the present probe, we used ascorbic acid to reduce $\mathrm{Fe}^{3+}$ in ferritin to $\mathrm{Fe}^{2+}$ under acidic conditions $(\mathrm{pH}$ 5.0). After undergoing a deproteinization process, the filtrates were subjected to direct measurements using our probe system. By applying a standard addition method, we obtained a linear plot $\left(R^{2}=0.987\right)$ of $\Delta \mathrm{Abs}_{827}$ with respect to the spiked $\mathrm{Fe}^{2+}$ concentrations over the concentration range from 0 to $10.0 \mu \mathrm{M}$. Using this relationship, we determined the concentration of $\mathrm{Fe}^{2+}$ to be $6.8 \pm 0.3 \mu \mathrm{M}$ (from five measurements), which agrees well with the value $(6.3 \pm 0.2 \mu \mathrm{M})$ obtained from five ICP-MS measurements. By considering the concentrations of $\mathrm{Fe}^{2+}$ and ferritin, we estimate that there are $310 \pm 10$ iron ions per ferritin unit.

We also expected that our $\mathrm{Au}-\mathrm{Ag}$ NR-based sensor would have great potential for use in the analysis of $\mathrm{Fe}^{2+}$ in environmental samples. We filtered a water sample from a pond on our campus through a $0.2-\mu \mathrm{m}$ membrane and then subjected the filtrate to analyses using the new probe system. Figure 5 displays the absorption spectra of the dilute pond water spiked with various concentrations of $\mathrm{Fe}^{2+}$ ions after addition of $\mathrm{CTAB}-\mathrm{Au}-\mathrm{Ag}$ NRs and PSS. Because the matrix effects were greater in this case than they were for the ferritin solutions, the plot of $\Delta \mathrm{Abs}_{827}$ with respect to the spiked $\mathrm{Fe}^{2+}$ concentration was nonlinear. Thus, we plotted the ratio of $\Delta \mathrm{Abs}_{1150}$ to $\Delta \mathrm{Abs}_{835}$ with respect to the spiked $\mathrm{Fe}^{2+}$ concentrations over the concentration range $0-2.0 \mu \mathrm{M}$; this plot was linear with a value of $R^{2}$ of 0.988 (inset of Figure 5). Using this relationship, we determined that the concentration of $\mathrm{Fe}^{2+}$ ion in the pond water was $1.2 \pm 0.1 \mu \mathrm{M}$; the value was $1.1 \pm 0.1 \mu \mathrm{M}$ when we performed the corresponding ICP-MS analysis. According to a $t$-test or $F$-test, the results from the two different measurements were not different based

(53) Harrison, P. M.; Andrews, S. C.; Artymiuk, P. J.; Ford, G. C.; Guest, J. R.; Hirzmann, J.; Lawson, D. M.; Livingstone, J. C.; Smith, J. M. A.; Treffry, A.; Yewdall, S. J. Adv. Inorg. Chem. 1991, 36, 449-486.

(54) Powell, A. K. Metal Ions in Biological Systems; Sigel, A., Sigel, H., Eds.; Marcel Dekker: New York, 1998; Vol. 35.

(55) Ford, G. C.; Harrison, P. M.; Rice, D. W.; Smith, J. M. A.; Treffry, A.; White, J. L.; Yariv, J. Philos. Trans. R. Soc. London, Ser. B 1984, 304, 551-565. (56) Gerlach, M.; Benshachar, D.; Riederer, P.; Youdim, M. B. H. J. Neurochem. 1994, 63, 793-807.

(57) Linert, W.; Jameson, G. N. L. J. Inorg. Biochem. 2000, 79, 319-326.

(58) Jellinger, K.; Paulus, W.; Grundke-iqbal, I.; Riederer, P.; Youdim, M. B.

H. J. Neural Transm. Parkinson's Dis. Dementia Sect. 1990, 2, 327-340.

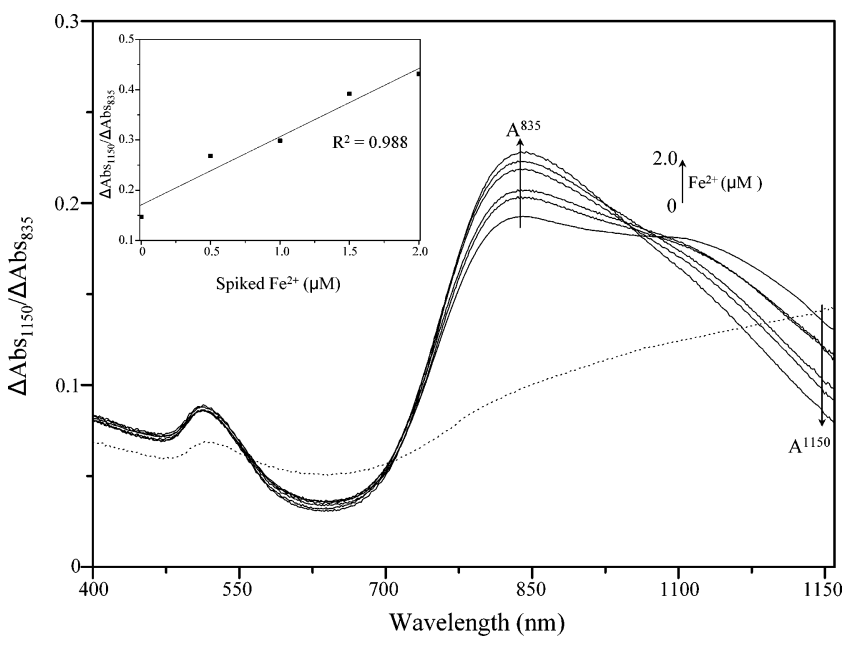

Figure 5. UV-vis absorption spectra of dilute pond water solutions after addition of CTAB $-\mathrm{Au}-\mathrm{Ag}$ NRs and $\left(5 \times 10^{-6}\right) \%$ PSS and spiking with $\mathrm{Fe}^{2+}$ ions at concentrations of $0,0.5,1.0,1.5$, and 2.0 $\mu \mathrm{M}$. The absorption spectrum (dotted line) of the CTAB-Au-Ag NR solution (1.0 mM Tris- $\mathrm{HCl}$ solution, $\mathrm{pH} 7.2$ ) in the presence of $\left(5 \times 10^{-6}\right) \%$ PSS is plotted as a reference. Inset: Plot of the $\Delta \mathrm{Abs}_{1150^{-}}$ to- $\Delta \mathrm{Abs}_{835}$ ratio with respect to the spiked $\mathrm{Fe}^{2+}$ concentration over the range from 0 to $2.0 \mu \mathrm{M}$.

on $95 \%$ confidence. Our results suggest that this probe will be useful for detecting environmentally relevant concentrations of $\mathrm{Fe}^{2+}$.

\section{Conclusions}

We have developed a colorimetric probe, based on CTAB$\mathrm{Au}-\mathrm{Ag}$ NRs in the presence of PSS, for the selective detection of $\mathrm{Fe}^{2+}$ ions. The charge dependence of $\mathrm{CTAB}-\mathrm{Au}-\mathrm{Ag} \mathrm{NR}$ agglomeration and the selectivity of the binding of PSS toward $\mathrm{Fe}^{2+}$ ions are the two most important parameters determining the sensitivity and selectivity of this probe. Our reasoning is supported by TEM, $\zeta$ potential, and absorption data. The present probe was sensitive toward $\mathrm{Fe}^{2+}(\mathrm{LOD}=1.0 \mu \mathrm{M})$, with high selectivity over most interference metal ions in aqueous solution. Judging from these results, we foresee great practical potential for various shaped $\mathrm{Au}-\mathrm{Ag}$ NRs that have outstanding optical properties, including strong and sharp longitudinal SPR absorption bands in the visible and near-infrared regions. To achieve the advantages of sensitivity, selectivity, and high throughput, bioconjugation of $\mathrm{Au}-\mathrm{Ag} \mathrm{NRs}$ is essential. In the future, we will focus on the preparation of various bioconjugated $\mathrm{Au}-\mathrm{Ag} \mathrm{NRs}$, which we hope can be used practically for the simultaneous analysis of several analytes of interest, such as metal ions and proteins.

Acknowledgment. This study was supported by the National Science Council (NSC 95-2113-M-002-026-MY3) of Taiwan.

LA701668E 